Metal-Catalyzed

Asymmetric

Synthesis and

Stereoselective

Reactions

\title{
Catalytic Asymmetric Allylic Alkylation with Vinylaluminum Reagents
}
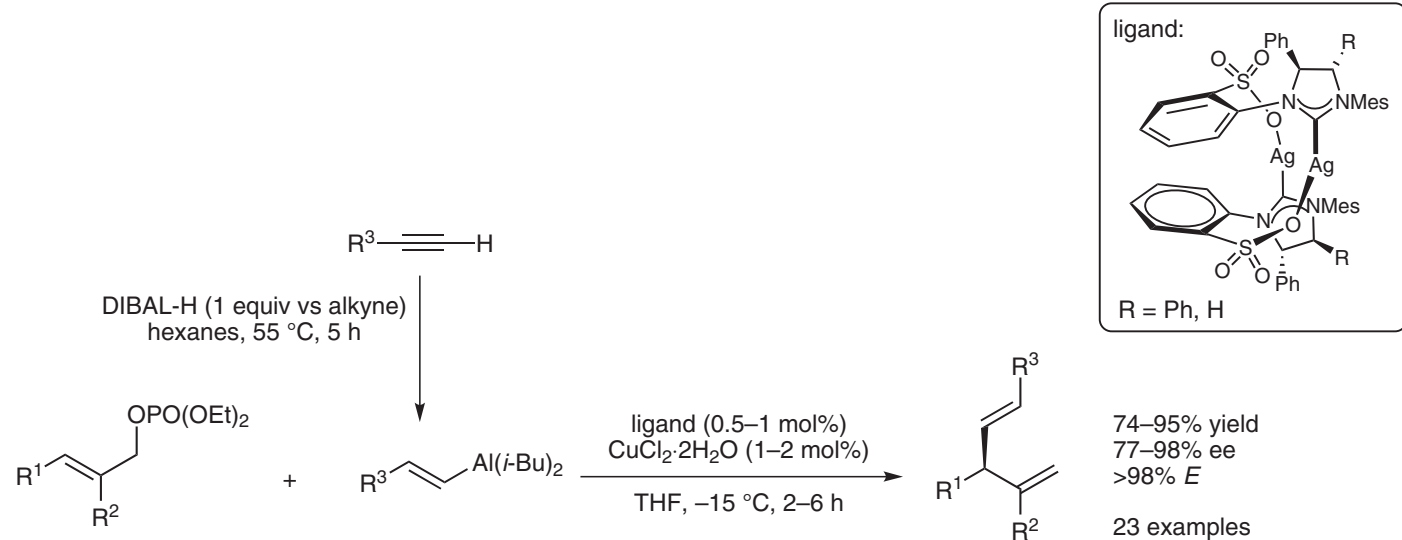

Selected examples:

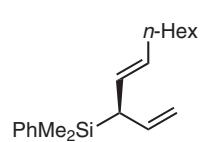

$91 \%$ yield $93 \%$ ee

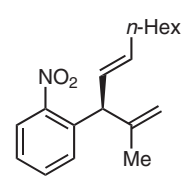

$94 \%$ yield $96 \%$ ee

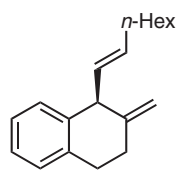

$95 \%$ yield

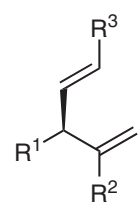

$74-95 \%$ yield $77-98 \%$

23 examples<smiles>C=C(C)C(/C=C/C1=CCCCC1)c1ccccc1</smiles>

$74 \%$ yield $90 \%$ ee

\section{Key words}

allylic alkylation

vinylaluminum

DIBAL-H

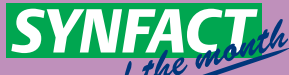

Significance: A new efficient method for catalytic asymmetric allylic alkylation of allylic phosphates with vinylaluminum reagents is reported. The desired products are obtained in good yields and with enantioselectivities up to $98 \%$ ee.
SYNFACTS Contributors: Mark Lautens, Valentina Aureggi Synfacts 2008, 3, 0267-0267 Published online: 21.02.2008 DoI: 10.1055/s-2008-1042697; Reg-No.: L00708SF
Comment: The vinylaluminum reagents are prepared and used in situ by reaction of commercially available DIBAL-H with terminal alkynes. The asymmetric allylic alkylations are promoted in the presence of a readily available chiral $\mathrm{N}$-heterocyclic carbene complex and a commercially available and air-stable copper salt. The desired products are obtained in relative short time (2-12 h) in $74-95 \%$ isolated yields, $77 \%$ to $>98 \%$ ee, and with $>98 \%$ E-selectivities. Various allylic phosphates can be used, including trisubstituted and disubstituted olefines. Vinyl bromides and cyclic alkenes are also suitable substrates for the allylic alkylation. A variety of terminal alkynes can be employed, including conjugated enynes. The hydroalumination/catalytic AAA sequence can be performed in a single vessel, on gram scale. 